\title{
Solid Organ Transplantation in Amyloidosis
}

\author{
Foteini Theodorakakou Despina Fotiou Meletios A. Dimopoulos \\ Efstathios Kastritis
}

Plasma Cell Dyscrasia Unit, Department of Clinical Therapeutics, National and Kapodistrian University of Athens, Athens, Greece

\section{Keywords}

Amyloidosis · Organ failure · Renal transplantation ·

Heart transplantation

\begin{abstract}
Amyloidosis comprises a diverse group of diseases characterized by misfolding of precursor proteins which eventually form amyloid aggregates and preceding intermediaries, which are deposited in target tissues causing progressive organ damage. In all forms of amyloidosis, vital organs may fail; depending on the specific amyloidosis type, this may occur rapidly or progress slowly. Beyond therapies to reduce the precursor protein (chemotherapy for light chain $[A L]$ amyloidosis, anti-inflammatory therapy in serum $A$ amyloidosis [AA], and antisense RNA therapy in transthyretin amyloidosis [ATTR]), organ transplantation may also be a means to reduce amyloidogenic protein, e.g., in types of amyloidosis in which the variant precursor is produced by the liver. Heart transplantation is a life-saving approach to the treatment of patients with advanced cardiac amyloidosis; however, amyloidosis may still be considered a contraindication to the procedure despite data supporting improved outcomes, similar to patients with other indications. Kidney transplantation is associated with particularly favorable outcomes in patients with amyloidosis, especially if the precur-
\end{abstract}

sor protein has been eliminated. Overall, outcomes of solid organ transplantation are improving, but more data are needed to refine the selection criteria and the timing for organ transplantation, which should be performed in highly experienced centers involving multidisciplinary teams with close patient follow-up to detect amyloid recurrence.

(c) 2020 S. Karger AG, Basel

\section{Introduction}

The term amyloidosis encompasses a heterogenous spectrum of diseases that result from the systemic or localized extracellular deposition of insoluble amyloid fibrils which cause disruption of the tissue architecture and progressive organ dysfunction. Up to date, at least 36 different precursor amyloidogenic proteins have been identified in humans [1], of which at least 17 cause systemic diseases [2]. Irrespective of the precursor, amyloid fibrils share common properties. Amyloid fibrils have a highly ordered $\beta$-pleated secondary structure which eventually results in stable amyloid aggregates via interaction with glycosaminoglycans and serum amyloid $\mathrm{P}$ protein [3].

Primary systemic light chain (AL) amyloidosis is the most common type of systemic amyloidosis, and the am- karger@karger.com

www.karger.com/aha

(C) 2020 S. Karger AG, Base

Karger"
Efstathios Kastritis, MD

Plasma Cell Dyscrasia Unit, Department of Clinical Therapeutics

National and Kapodistrian University of Athens

80 Vassilisis Sofias Avenue, GR-11528 Athens (Greece)

ekastritis@gmail.com or ekastritis@med.uoa.gr 
Table 1. Solid-organ transplantation in systemic amyloidosis

\begin{tabular}{|c|c|c|}
\hline $\begin{array}{l}\text { Type of } \\
\text { amyloidosis }\end{array}$ & $\begin{array}{l}\text { Organ considered } \\
\text { for transplantation }\end{array}$ & $\begin{array}{l}\text { Reason for } \\
\text { transplantation }\end{array}$ \\
\hline $\mathrm{AL}$ & $\begin{array}{l}\text { Kidney } \\
\text { Heart } \\
\text { Liver }\end{array}$ & $\begin{array}{l}\text { Salvage therapy } \\
\text { Salvage therapy } \\
\text { Salvage therapy }\end{array}$ \\
\hline ATTRwt & Heart & Salvage therapy \\
\hline ATTRm & $\begin{array}{l}\text { Liver } \\
\text { Heart }\end{array}$ & $\begin{array}{l}\text { Etiological therapy } \\
\text { Salvage therapy }\end{array}$ \\
\hline $\mathrm{AA}$ & Kidney & Salvage therapy \\
\hline AFib & $\begin{array}{l}\text { Kidney } \\
\text { Liver }\end{array}$ & $\begin{array}{l}\text { Salvage therapy } \\
\text { Etiological therapy }\end{array}$ \\
\hline ALys & $\begin{array}{l}\text { Kidney } \\
\text { Liver }\end{array}$ & $\begin{array}{l}\text { Salvage therapy } \\
\text { Etiological therapy }\end{array}$ \\
\hline AApoI & $\begin{array}{l}\text { Kidney } \\
\text { Liver } \\
\text { Heart }\end{array}$ & $\begin{array}{l}\text { Salvage therapy } \\
\text { Etiological therapy } \\
\text { Salvage therapy }\end{array}$ \\
\hline AApoII & Kidney & Salvage therapy \\
\hline ALect2 & Kidney & Salvage therapy \\
\hline
\end{tabular}

AL, light-chain amyloidosis; AA, serum A amyloidosis; ATTR, transthyretin amyloidosis; ALys, lysozyme amyloidosis; AFib, fibrinogen amyloidosis; AApoI, apolipoprotein I amyloidosis; AApoII, apolipoprotein II amyloidosis; ALect2, leukocyte cellderived chemotaxin-2 amyloidosis.

yloid originates from variable regions of monoclonal immunoglobulin light chains, produced by a usually indolent plasma or B-cell clone. Clinical presentation is dependent upon organ tropism of the amyloidogenic light chain and the extent of organ dysfunction. Most commonly affected vital organs include the kidneys, heart, liver, peripheral nervous system, soft tissue, gastrointestinal tract, and less often the lung [4]. Agents that target the plasma/B-cell clone are currently the mainstay of treatment [5]. Recent breakthrough advances in chemoimmunotherapy have led to improved outcomes and overall survival [5-7], but the disease remains fatal as organ function is often unsalvageable, and diagnosis is made at advanced stage. A significant proportion of patients will present with end-stage heart failure and a very poor life expectancy, others will present with end-stage renal dysfunction (ESRD), and more will eventually develop ESRD requiring dialysis; it is rather rare that patients with AL amyloidosis may present with end-stage liver dysfunction.
The second most common type of amyloidosis is caused by the deposition of amyloid fibers formed by misfolded transthyretin (TTR), a transport protein which is secreted by the liver that carries thyroxine (T4) and retinol (vitamin A1) in the serum. Wild-type ATTR or senile systemic amyloidosis is an acquired form of amyloidosis which affects mainly the elderly population and causes cardiomyopathy. The hereditary form of ATTR is caused by mutations in the TTR gene, is inherited in an autosomal dominant manner, is encountered in younger populations, and mainly manifests as peripheral neuropathy and heart failure, with varying degrees of relative severity of these 2 major systems, depending on the type of mutation [8].

Serum A (AA) amyloidosis is a form of secondary amyloidosis, associated with underlying chronic inflammatory disorders (rheumatoid arthritis, chronic infections, and periodic fever syndromes) [9]. The precursor protein for amyloid fibrils is the serum amyloid A (SAA) protein, an acute-phase reactant protein produced by the liver. Clinically, AA is almost always characterized by renal involvement, which presents as a nephrotic syndrome and with progressive decline in renal function, and ESRD if left untreated $[9,10]$. Other, rarer types of amyloidosis may occur from mutated lysozyme (ALys), fibrinogen (AFib), apolipoprotein AI or AII, and leukocyte-derived chemotaxin-2, all of which induce hereditary systemic syndromes and affect organs such as the liver and the kidney, and less often the heart (Table 1).

The management of end-stage organ failure (cardiac, renal, or liver) in patients with amyloidosis is significantly more complex than in patients without amyloidosis. Prognosis and life expectancy $[11,12]$, and quality of life is reported to be worse, although in the past decade there has been a major improvement in outcomes [13]. Possible explanations include multi- rather than single-organ dysfunction with concurrent involvement of the autonomic nervous system, which complicates the management of cardiac failure and dialysis therapy. Given the rarity of all types of amyloidosis and the even lower rates of suitable candidates for organ transplantation, reports on amyloidosis patients with kidney, heart (HT), and liver transplantation (LT) are scarce, and patient cohorts are often small and heterogenous. The lack of generalized criteria that determine patient eligibility leads to selection bias and limits the quality of data. Available data on solid organ transplantation will be reviewed in this study to elucidate how this treatment option can fit into the treatment algorithm of these patients. 


\section{Solid Organ Transplantation in AL Amyloidosis}

Current Status in the Management of AL Amyloidosis

Almost any organ or tissue may be affected by AL amyloidosis, and the immunoglobulin light chain variable region (IGLV) gene family of the involved clone seems to play a significant role in organ tropism [14-16]. Renal involvement is seen in approximately $70 \%$ of patients, and about $30 \%$ will require dialysis due to ESRD [17-20]. The heart is involved in $60-70 \%$ of cases and is the most critical factor for prognosis, and about $10-20 \%$ of patients present with severe or terminal-stage heart failure with a poor prognosis and an expected median survival of 4-12 months [21-23]. Finally, hepatic AL amyloid with hyperbilirubinemia is also associated with very poor outcomes (<4 months) $[24,25]$.

Treatment and monitoring of patients with AL amyloidosis has evolved over the past 20 years, and this has affected the place of organ transplantation in the treatment plan for these patients. The extent of cardiac involvement is the major determinant of outcome in patients with $\mathrm{AL}$ amyloidosis, and risk assessment is mainly based on NTproBNP and cardiac troponins [21, 26-28]. A renal staging system based on proteinuria and glomerular filtration rate is also available [17] with advancedstage patients having a very high probability of progression to dialysis within 2 years from the start of therapy.

A critical aspect of AL amyloidosis therapy is the assessment of hematologic response, the degree and depth of which may be a critical factor when organ transplantation is considered or planned. Reduction in the concentration of the clonal immunoglobulin levels (of the circulating free light chains) is the strongest predictor for prolonged survival and for organ function improvement [29], and a critical factor that may affect post-organ transplantation outcome. However, even among patients who have achieved a complete hematologic response, organ function may continue to deteriorate, either due to irreversible organ damage or due to residual production of toxic immunoglobulins, which is undetected by standard methods. New tools to detect minimal residual disease, such as next-generation flow cytometry, next-generation sequencing, and serum and urine mass spectrometry, are now incorporated into clinical practice to assess depth of response and tailor the therapeutic plan [30-33], which may also include decisions concerning organ transplantation.

Treatment of AL amyloidosis is risk adapted and tailored to the patient's characteristics, but organ involvement patterns and the severity of dysfunction are the main determinants [5,34]. High-dose melphalan plus au- tologous stem cell transplantation (ASCT) is associated with favorable outcomes in selected patients $[35,36]$, but mostly the introduction of novel regimens, which include proteasome inhibitors (bortezomib, ixazomib, and carfilzomib) [37-39], immunomodulators (lenalidomide and pomalidomide) [40-42], monoclonal anti-CD38 antibodies (daratumumab) [43], and their combinations have resulted in improved hematologic response rates. These improvement have led to improved organ responses, which may be translated into more patients being able to avoid terminal organ failure, but also more long-term survivors who may be in need of organ transplantation after gradual failure of an affected organ, for example ESRD, while in complete hematologic remission.

\section{Solid Organ Transplantation in AL Amyloidosis}

The short-term goal of treatment is the rapid reduction in the circulating toxic FLC and the long-term improvement in organ response and eventually prolonged survival.

Unfortunately, in a significant proportion of patients, organ damage is irreversible at the time of diagnosis. In addition, patients with end-stage cardiac disease and hepatic failure are often unsuitable candidates for chemoimmunotherapy and cannot tolerate anticlonal therapies to suppress the aberrant plasma cell clone [2, 5].

Solid organ transplantation in patients with $\mathrm{AL}$ amyloidosis may require a rapid assessment and decision making when this concerns end-stage cardiac failure, or it may be a decision that can be made on a more mid-term basis.

For several years, the role of solid organ transplantation in the management of AL amyloidosis remained a rather debatable issue, mainly due to concerns of early graft failure and amyloidosis recurrence in the allograft or other tissues $[44,45]$. Organ donor shortage complicates the issue further. The introduction of new therapies which can induce very deep and long-lasting hematologic responses have changed this perception $[13,46,47]$.

\section{Renal Transplantation in AL Amyloidosis (Table 2)}

Historically, the first case of kidney transplantation in an AL patient was reported by Belzer et al. [48]. During the following years, kidney transplantation was rather rarely performed in patients with AL amyloidosis, but the evolving anticlonal options have changed the field landscape. A major barrier in clinical practice remains the lack of established eligibility criteria to determine candidates for transplantation and when they should be considered for renal transplants. Over the last 2 decades, few retro- 
Table 2. Comparison of major outcomes of renal transplantation in patients with amyloidosis

\begin{tabular}{|c|c|c|c|c|c|c|}
\hline $\begin{array}{l}\text { Amyloid } \\
\text { type }\end{array}$ & Center & $\begin{array}{l}\text { Patients, } \\
n\end{array}$ & $\begin{array}{l}\text { Median OS, } \\
\text { years }\end{array}$ & $\begin{array}{l}\text { 5-year } \\
\text { survival, \% }\end{array}$ & $\begin{array}{l}\text { Median graft } \\
\text { survival, years }\end{array}$ & $\begin{array}{l}\text { 5-year graft } \\
\text { survival, \% }\end{array}$ \\
\hline $\mathrm{AL}$ & US Renal Data System & & N/A & $86.1 / 93.1$ & 9.1 & $72.4-84.6$ \\
\hline $\mathrm{AL}$ & Mayo Clinic & 22 & $\mathrm{~N} / \mathrm{A}$ & $\mathrm{N} / \mathrm{A}$ & N/A & N/A \\
\hline $\mathrm{AL}$ & UK NAC & 52 & 6.5 & 67 & 5.8 & 53 \\
\hline $\mathrm{AA}$ & UK NAC & 43 & N/A & N/A & 10.3 & 86 \\
\hline ALys & UK NAC & 3 & N/A & 100 & 13.1 & 100 \\
\hline AFib & UK NAC & 19 & N/A & N/A & $\begin{array}{l}7.3 \text { (in isolated KT) } \\
6.4 \text { (in CLKT) }\end{array}$ & $\begin{array}{l}85 \% \text { (in isolated KT) and } \\
63 \% \text { (in CLKT) }\end{array}$ \\
\hline AApoI & UK NAC & 14 & $\mathrm{~N} / \mathrm{A}$ & 100 & 13.1 & 100 \\
\hline
\end{tabular}

AL, light chain amyloidosis; AA, serum A amyloidosis; ATTR, transthyretin amyloidosis; ALys, lysozyme amyloidosis; AFib, fibrinogen amyloidosis; AApoI, apolipoprotein I amyloidosis; KT, kidney transplantation; CLKT, combined liver and kidney transplantation; NAC, National Amyloidosis Centre.

spective studies demonstrated encouraging data in meticulously selected AL patients, although the small sample size constitutes a major limitation secondary to selection bias. In a series of 22 renal transplant patients with $\mathrm{AL}$ amyloidosis and established ESRD from the UK National Amyloidosis Centre (NAC), median graft survival was 5.8 years, and median overall survival (OS) from the time of renal transplantation was 6.5 years (range 0.2-13.3) [47], and 1- and 5-year OS was 95 and 67\%, respectively. The general inclusion criteria for renal transplantation were age $<70$ years and ECOG performance status of 1 or 2, while patients with symptomatic myeloma or extensive extrarenal amyloidosis were excluded. In this cohort, most patients had anticlonal therapy, either chemotherapy, immunotherapy, or ASCT before the time of renal transplantation, but this cohort included mostly patients treated before the introduction of bortezomib and other new therapies. There are older data to support that plasma cell-targeted therapy should preferably be administered prior to renal transplantation to stop the production of "toxic" free light chains and protect the function of the renal allograft [49]. However, currently, more treatment options are available, and this may not be absolutely necessary. Leung et al. [50] published a series of 8 patients who received renal transplants from living donors followed by ASCT. Two of the patients suffered unanticipated complications after kidney transplantation, 2 had subclinical acute rejection, and 1 had clinical cellular rejection, which were all reversible with corticosteroid therapy; 6 patients had successful stem cell harvests, and 5 underwent ASCT, and renal function remained stable following ASCT in 4 and deteriorated in 1 due to inftious and bleeding complications. Importantly, 1 patient, who elected not to undergo ASCT, had histologic evidence of recurrent renal amyloidosis. In 2011, the Mayo Clinic published another series of 19 patients with AL amyloidosis that underwent renal transplantation (18 from living donors) before the bortezomib era. This cohort also included the previous 8 patients who had a renal transplantation before ASCT and compared them to patients who had ASCT followed by renal transplantation (6 patients), and another 5 patients who had renal transplantation after complete response (CR) that was achieved with nonmyeloablative therapy. The authors found no difference in survival rates between the 3 groups, and recurrent amyloidosis was diagnosed following biopsy in 1 patient who had ASCT before renal transplantation and in another patient that received a transplant while in complete hematologic response without ASCT [51].

In another series of 25 patients with AL who underwent renal transplantation in the UK, no significant difference in graft survival between those who had achieved $\mathrm{CR}$ and those who were in partial response (PR) was reported. In addition to the above, the attainment of at least a PR at the time of kidney transplantation led to better overall graft survival when compared with those who had no response ( 8.9 vs. 5.2 years, $p=0.02$ ) [52].

Recent data, coming from the Amyloidosis Center in Boston, based on the long-term follow-up of 49 patients who received kidney transplants (the largest cohort so far), are very encouraging [53]. The patients in this report received kidney transplants between 1987 and 2017, and median survival from the time of renal transplantation was 10.5 years (range 1-27.7), while median graft surviv- 
Table 3. Survival after heart transplantation (HT)

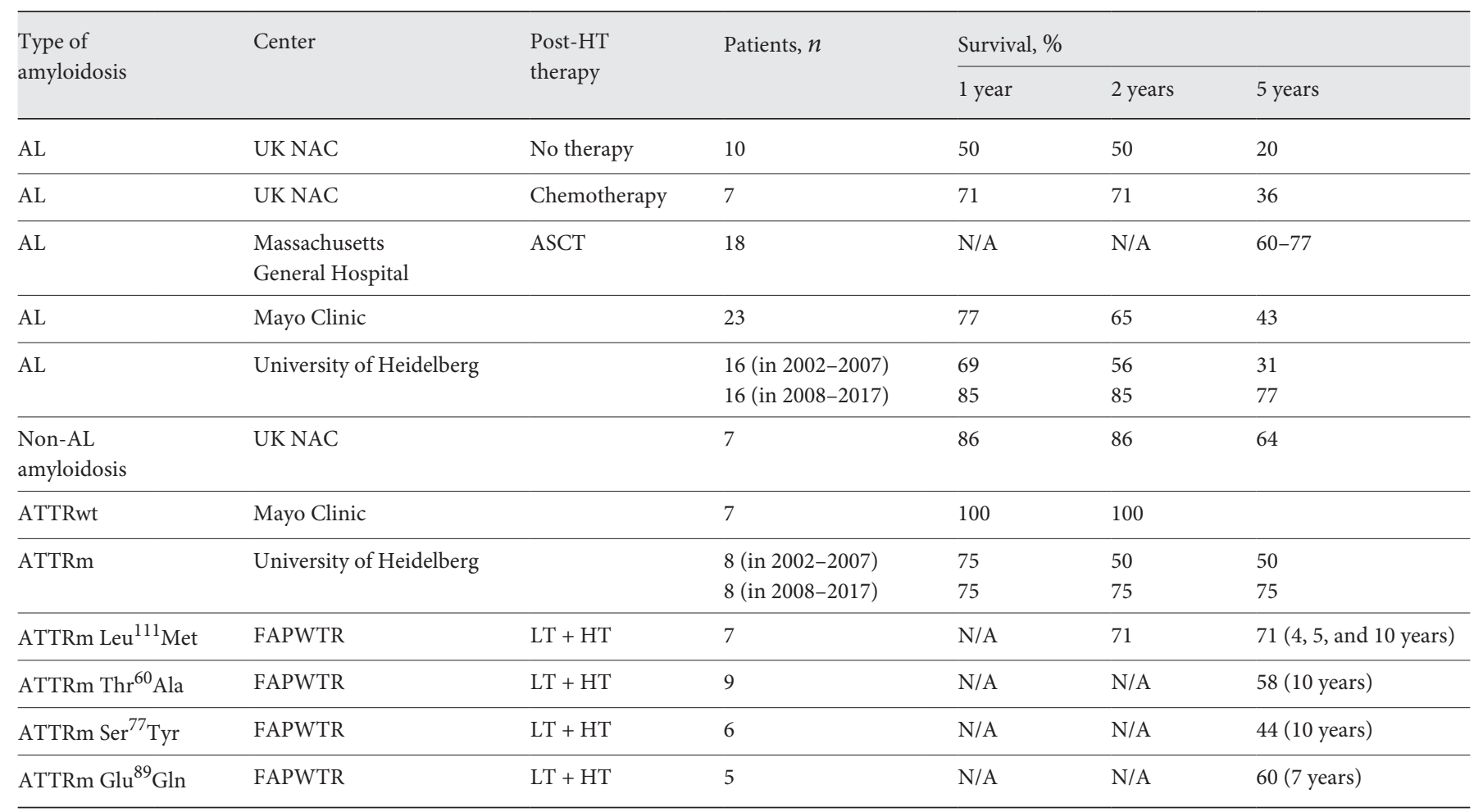

AL, light chain amyloidosis; ATTRwt, wild-type transthyretin amyloidosis; ATTRm, mutated transthyretin amyloidosis; NAC, National Amyloidosis Centre; FAPWTR, Familial Amyloid Polyneuropathy World Transplant Registry.

al was 8.3 years (range 0.3-20.3). Graft survival at 1-, 3-, and 5 -years was 94,89 , and $81 \%$, respectively. In comparison with the results from the NAC in the UK and the Mayo Clinic almost a decade ago, there was clearly an improvement in both overall and graft survival similar to outcomes achieved with renal transplantation for other etiologies.

Clinical or pathological indicators of disease recurrence in the graft were reported in $4(15 \%)$ patients with CR or very good PR versus in 11 (69\%) patients with no or PR at the time of kidney transplantation, emphasizing the importance of deeper hematologic response to improve graft survival. When divided according to the date of renal transplantation, survival from diagnosis was better in the last decade (2007-2017) than the 2 previous (1987-2006) ones, but survival from transplantation, graft survival, and time to recurrence of amyloid in the graft were also improved during the same period although the difference did not reach statistical significance.

Despite the strong rationale behind the performance of renal transplantation following chemotherapy, it is extremely challenging to perform a head-to-head compari- son of the 2 approaches due to the rarity of the disease and the difficulty in selecting suitable candidates [54]. Currently, a deep hematologic response (CR or very good PR) is considered by most clinicians a prerequisite for renal transplantation $[55,56]$. Based on the available data, markedly better posttransplant outcomes and improved graft survival have been achieved after the introduction of novel and more effective therapies. Since more patients are now achieving deep and sustainable hematologic responses, renal transplantation could be further pursued as a treatment for selected patients, and the diagnosis of $\mathrm{AL}$ amyloidosis should not be an exclusion criterion for kidney transplantation [55]. Definite selection criteria do not exist; however, it is reasonable to consider patients with either isolated renal AL or patients without severe dysfunction of other involved organs who have achieved at least a very good PR. In some patients, further therapy to improve hematologic response after renal transplantation may also be a feasible option, including ASCT. Ongoing data collection of patients with $\mathrm{AL}$ who have received kidney transplants in the more recent era may help to further clarify selection criteria for optimal outcomes. 


\section{HT in AL Amyloidosis (Table 3)}

The prognosis in patients with cardiac AL amyloidosis is ominous, and the survival of patients with severe cardiomyopathy is about 4-12 months [57], with a high risk of early death. The main causes of death are decompensated end-stage heart failure and sudden death. Unfortunately, the benefits of novel agent combinations in terms of response rates and OS have not been translated into major improvement in the subset of patients with advanced stage (Mayo stage IIIb or revised Mayo stage IV patients) [22]. The risk of early mortality may also increase due to poor tolerance of the chemotherapeutic regimens, although it may be difficult to prove the exact cause and association. HT may represent the only viable solution for patients with end-stage heart failure who are also unable to tolerate chemoimmunotherapy, but the limited organ availability significantly narrows its clinical appliance [58].

The first reported HT for cardiac amyloidosis was in 1984 [59] followed by small numbers of heart transplants in the following decade $[45,60]$. In a report from 2004 of 17 patients with $\mathrm{AL}$ amyloidosis, the survival of $10 \mathrm{pa}-$ tients who had HT but no additional chemotherapy was 50,50 , and $20 \%$ at 1,2 , and 5 years, respectively, while the amyloid recurred in the grafts of these patients after a median of 11 months, and extracardiac amyloidosis contributed to mortality in $70 \%$ of these patients. Among the 7 patients who also had chemotherapy, survival at 1,2 , and 5 years was 71,71 , and $36 \%$, respectively, and 1 patient had amyloid recurrence in the graft at 60 months. The 5-year survival after HT in patients with AL amyloidosis was less than that after HT for other indications [45]. In another report from the UK, 14 patients had a median survival of 6.3 months after diagnosis of amyloidosis. At the time of HT, 8 patients had no extracardiac amyloidosis, but 6 had amyloidotic dysfunction of additional organs. The median survival from HT was 7.5 years. The median survival of the 8 patients who underwent ASCT after HT was 9.7 years compared to 3.4 years for those without ( $p=0.01$ ), but no patient who underwent ASCT after HT had major extracardiac organ dysfunction at the time of ASCT.

Importantly, 5 patients received chemotherapy before $\mathrm{HT}$, and all achieved a hematologic $\mathrm{PR}$, and 11 received chemotherapy after HT, including ASCT in 8 patients. Amyloid recurred in the cardiac allografts of 5 patients, all of whom had persistence or relapse of their clonal disease. Four of 5 patients with recurrence died, and another 3 died from progressive extracardiac amyloidosis. In a retrospective observational analysis of 31 patients with heart failure attributed to AL amyloidosis in the Massachusetts General Hospital, 18 (58.1\%) patients survived to receive HT, $11(35.4 \%)$ did not, while 2 patients remained on the HT waiting list [13]. The average time from entering the list to transplant was $53 \pm 48$ days for those who survived HT and $63 \pm 45$ days for those who died before HT. Patients who survived had lower free light chain load than patients who did not survive to HT $(p=0.05)$, and they tended to have lower BMI $(p=0.05)$. In comparison with patients listed for nonamyloid cardiomyopathies, patients with AL amyloidosis had a mortality hazard ratio of $4.7(p<0.001)$, but survival after HT was the same for amyloid and nonamyloid patients. According to data from the Mayo Clinic [11], in $23 \mathrm{HT}$ patients with $\mathrm{AL}$ amyloidosis with a median age of 53 years, there were no deaths in the immediate perioperative period, and the median overall survival of the cohort was 3.5 years, with 1-, 2-, and 5-year survival after transplant being 77,65 , and $43 \%$, respectively; notably, for nonamyloid patients undergoing HT during the same era, 5-year survival was $85 \%$. This series included many patients treated in the era before new therapies became available, and progressive amyloidosis was associated with death in 12 (52\%) patients. Eight patients had evidence of graft rejection, but only 1 of them died. The median survival was 6.3 years for patients who received ASCT versus 2.4 years for patients who did not, but response depth was critical: median OS was 1.2 years for non-responders, 5.4 years for patients who achieved very good $\mathrm{PR}$ or $\mathrm{PR}$, and almost 11 years for patients who achieved a hematologic CR to either chemotherapy or ASCT. Another common issue of debate is the role of ASCT in patients who are candidates for HT and the optimal timing of the 2 transplants. An ASCT before CHT is not feasible, since these patients are at extremely high risk of death during ASCT [36]. However, the 5-year survival increases significantly to $60-77 \%$ when HT is followed by ASCT [11, 13, 45, 61, 62]. The interval between HT and ASCT depends on the hematologic response status and on the timing of immunosuppressive treatment cessation to allow minimization of infection risk post-ASCT, and the optimal time between HT and ASCT is probably $6-8$ months $[63,64]$. Today, however, available therapies may be safer and at least or more effective than ASCT [65-67].

According to the recommendations from the 2016 International Society for Heart and Lung Transplantation, meticulously selected patients with heart failure due to $\mathrm{AL}$ amyloidosis who cannot tolerate other treatment due to cardiovascular compromise may be suitable candidates for HT in highly experienced centers with established col- 
laborations between cardiovascular and hematology teams (class IIA, level of evidence: B) [63]. However, the largest constraint in the process of $\mathrm{HT}$ in $\mathrm{AL}$ amyloidosis is the long waiting list, which in association with endstage heart dysfunction and treatment intolerance leads to very low survival rates, with very few patients finally reaching HT $[11,12]$. It remains debatable whether patients with AL amyloidosis who need HT to survive may have a similar benefit as other patients requiring transplants for other diseases; given the scarcity of cardiac grafts, this is relevant and one of the most commonly used arguments delaying the selection of patients with AL amyloidosis or excluding them from transplant lists. However, this is probably not the case anymore. In a retrospective analysis of 48 patients who were diagnosed with cardiac amyloidosis and underwent HT during 2 different periods (2002-2007 and 2008-2017), the 5-year survival rate post-HT was $31 \%$ in the first period and $77 \%$ in the second [13]. What is most important is that the 5-year survival rates during the second period were comparable to those of nonamyloid patients. Plausible explanations include improved, more stringent selection criteria and improved hematologic responses secondary to improved treatment options. Taking emerging novel treatments with more manageable toxicity profiles into consideration, survival before and after HT is expected to improve in the future. Furthermore, circulatory support with intravenous inotropes or mechanical support using left- or biventricular assist devices may offer the additional time required while waiting for HT [13, 68-70]. Current HT selection criteria, which are not validated, include primary cardiac organ involvement, absence of significant extracardiac organ involvement, lack of organ response despite treatment administration, and attainment of hematologic response prior to HT [11]. However, concomitant or tandem heart and kidney transplantation have been reported and were associated with a good outcome in carefully selected patients [71].

\section{LT in AL Amyloidosis}

Patients with severe liver dysfunction have a very poor outcome [25] and present usually with multisystemic involvement [72]. Data on LT for patients with AL amyloidosis are very limited. Patients with dominant hepatic involvement are poor candidates for chemoimmunotherapy as they will rarely tolerate regimens even at adjusted doses. In that context, LT could be a reasonable alternative. In an NAC series, 9 patients received orthotopic LT (OLT) with 1- and 5-year survival from transplantation of 33 and 22\%, respectively [47]. Six patients received chemotherapy (including ASCT in 3 patients) after OLT, and, interestingly, 4 patients developed rapidly progressive proteinuria secondary to preexisting renal amyloidosis. Thus, the experience with OLT in patients with AL amyloidosis is very limited, and more data are required to determine whether there is a place for LT in decompensated patients.

\section{ATTR Amyloidosis and Solid Organ Transplantation}

In contrast to AL amyloidosis, ATTR amyloidosis is progressing at a slower pace with gradual and incremental worsening of neuropathy and gastrointestinal symptoms in case of mutated ATTR (ATTRm) with dominant neuropathy or with usually slowly progressing cardiomyopathy with gradual ventricular wall thickening, deterioration of diastolic function, and appearance of conduction disorders [73].

It has been documented that the type of mutation in ATTRm affects the disease phenotype and prognosis to a considerable extent. The most common mutation causing a mainly neuropathic or mixed neuropathic/cardiomyopathy phenotype (familial amyloid polyneuropathy [FAP]) is a valine-to-methionine substitution at position 30 ( $\left.\mathrm{Val}^{30} \mathrm{Met}\right)$. Series and data from patients with mutations other than $\mathrm{Val}^{30} \mathrm{Met}$ are significantly more limited. The 10 -year survival for non-Val ${ }^{30}$ Met mutations varies markedly from $21 \%$ for $\mathrm{Ser}^{50} \mathrm{Arg}$ to $85 \%$ for $\mathrm{Val}^{71} \mathrm{Ala}$ [74]. The most common mutation associated with cardiac ATTR is the valine-to-isoleucine substitution at position $122\left(\mathrm{~V}^{122} \mathrm{I}\right)$.

Given that the liver is the main source of amyloid precursor protein, LT was the only established therapy since 1990 [75] until recently. Survival following LT depends on the mutation variant. Five-year survival following LT was almost $100 \%$ for carefully selected $\mathrm{Val}^{30}$ Met patients $[76,77]$, while the 5 -year survival was $59 \%$ for non$\mathrm{Val}^{30} \mathrm{Met}$ patients [78]. LT was also associated with a positive impact on the quality of life as deterioration of nerve dysfunction, which renders patients helpless and frail over the course of the disease, was prevented. The main causes of mortality after LT in $\mathrm{Val}^{30}$ Met patients, however, beyond sepsis and malnutrition, were also cardiac complications.

LT for ATTRm was significantly fostered as a viable treatment approach by the concept of domino liver transplantation (DLT), which emerged in the 1990s. The idea of reusing the liver graft originating from patients with metabolic diseases who undergo LT themselves has some 
benefit. Most importantly, the liver donor pool is expanded, and grafts become available for aged patients with cirrhotic liver or hepatocellular cancer. Patients with FAP were the first domino liver transplant donors for various reasons. Their liver was considered ideal given their relatively young age (frequently under 50 years of age). Moreover, the liver of FAP patients is architecturally and functionally normal. The primary skepticism regarding domino liver transplants remains amyloid production, despite the fact that it takes almost 30 years for amyloid fibrils to form, deposit in target organs, and cause symptomatic disease [79]. The first case of de novo ATTR following domino liver transplants was reported in 2005 in a 55-year-old patient who developed progressive peripheral neuropathy of the lower extremities 8 years after the transplantation [80]. Other case reports followed. FAP presents at approximately 7-9 years following domino LT, which is earlier than expected [81, 82 ] by the natural history of the disease. Factors that interfere with the natural history of the disease may play a role in the development of de novo ATTR. For instance, the use of immunosuppression to prevent organ rejection following DLT might contribute to the acceleration of ATTR symptoms in liver graft recipients from an FAP donor. The recipient's age might be another contributing factor. Development of cardiac ATTR after LT for FAP has also been reported [83]. Thus, clinicians have to be conscious of amyloid development in recipients of such grafts, and screening protocols are required for their assessment.

Since ATTRm may also present with a mixed or predominantly cardiac phenotype, which leads to end-stage heart failure, HT has been combined with LT. The 10year survival in ATTRm patients with cardiac involvement ranged from 47 to $71 \%$ [13, 74]. Isolated HT has been performed in selected patients with end-stage heart failure and absence of extracardiac amyloidosis. Importantly, the outcomes of patients with ATTRm receiving cardiac grafts has been very similar to that of patients with other indications for cardiac transplants [13].

Non- $\mathrm{Val}^{30} \mathrm{Met}$ patients with cardiac involvement may also be candidates for LT and HT. The 5-year graft survival was satisfactory, but there were concerns regarding amyloid recurrence secondary to TTR production by the liver $[84,85]$. Combined LT-HT has also been performed $[86,87]$. Patients with familial TTR cardiac amyloidosis should be considered for combined HT-LT in highly specialized centers with established collaboration between cardiology, hepatology, and neurology teams (class IIA, level of evidence: B) [63].

Solid Organ Transplantation in Amyloidosis
For patients with wild-type ATTR (ATTRwt), LT has no place, since the disease is caused by non-mutated TTR. However, HT may be considered in selected patients, but most patients with ATTRwt are quite elderly and not eligible for HT. In a small cohort of 7 patients with ATTRwt (all male, with a mean age of $66 \pm 9$ years) who underwent HT between 2007 and 2015, the 3-year survival was 100\%, and 1 patient died due to pancreatic cancer 45 months after transplant [88]. However, symptomatic gastrointestinal involvement (in 2 patients) and peripheral nerve involvement (in 4 patients) by ATTRwt developed subsequently.

Treatment options for patients with hereditary ATTR and ATTRwt are expanding. TTR tetramer stabilizers (such as tafamidis), which bind to the thyroxine-binding site of TTR, prevent the formation of $\beta$-pleated insoluble oligomers and inhibit amyloidogenesis. Tafamidis has received approval for patients with FAP in Europe and Japan $[89,90]$ and for patients with ATTRwt in the USA and Europe based on a randomized study [91]. RNA interference agents are able to control TTR production via interference with TTR messenger RNA and substantially reduce hepatic TTR synthesis, which suppresses amyloid production. Based on 2 different prospective randomized trials in patients with ATTRm neuropathy, 2 RNA-interfering agents, inotersen and patisiran, have been approved for the treatment in patients with hereditary TTR amyloidosis [92, 93]. These agents also seem to affect favorably cardiac amyloidosis $[94,95]$ due to ATTRm and are under investigation for other indications and ATTRwt. Agents that target amyloid deposits to assist in their clearance are also in clinical development.

\section{AA Amyloidosis and Organ Transplantation}

Renal involvement is seen in most cases of AA amyloidosis, which eventually progresses to ESRD. Efforts to pharmacologically delay the progression of renal disease have poor results $[9,96]$. A large multicentric retrospective survey in France presented data from 59 patients with AA amyloidosis and ESRD who underwent renal transplantation [97]. The cohort included 25 patients with chronic inflammatory disorders (inflammatory arthritis, Still's disease, Crohn's disease, and Hodgkin's lympho$\mathrm{ma}), 21$ patients with hereditary periodic fever syndromes (familial Mediterranean fever, Schnitzler's syndrome, and tumor necrosis factor receptor-associated periodic syndrome), 10 patients with chronic infections (tuberculosis and cystic fibrosis), and 3 patients with undetermined primary etiology for AA amyloidosis. Prior to re-

Acta Haematol 2020;143:352-364

DOI: $10.1159 / 000508262$ 
nal transplantation, $49.1 \%$ of patients had been treated with steroids, and $26.3 \%$ had received immunosuppressive drugs, including colchicine for familial Mediterranean fever. Median time from AA diagnosis to ESRD was 3 years, and median time from ESRD to renal transplantation was 2.6 years. The median follow-up time was 5.5 years, and 5 - and 10 -year survival rates were significantly lower compared to the control group ( 82.5 vs. $94.2 \%$ at 5 years, $p=0.028$, and 61.7 vs. $83.4 \%$ at 10 years, $p=0.013$, respectively). Biopsy-proven recurrence of renal AA occurred in 8 patients (14\%), leading to allograft loss in 4 patients. Death was mainly due to cardiovascular complications and severe infections, and mortality was increased compared to the control group.

In another series of $43 \mathrm{AA}$ patients who underwent renal transplantation, SAA levels were measured 6 months prior to transplantation. Allograft survival and recurrence of amyloidosis correlated with SAA levels. Graft survival was 14.5 years in patients with SAA levels $<10 \mathrm{mg} / \mathrm{L}$, and 7.8 years in those with SAA $>10 \mathrm{mg} / \mathrm{L}$, but this difference was not statistically significant; however, median SAA value was significantly higher among patients with recurrent kidney amyloidosis $(p=0.04)$ [52]. Thus, close follow-up is required after transplantation, and SAA level monitoring could be utilized to determine high-risk patients for allograft amyloid recurrence. New treatments may offer additional options to control inflammation after kidney transplantation and reduce the risk of recurrence [98-100]. Although data are scarce, given the limited availability of therapeutic options, following careful patient selection, renal transplantation seems currently to be a suitable therapeutic approach for patients with AA amyloidosis with ESRD.

\section{Organ Transplantation in Other Types of Amyloidosis}

Lysozyme amyloidosis (ALys) is a hereditary form of systemic nonneuropathic amyloidosis, which is inherited in an autosomal dominant fashion. The precursor protein is lysozyme, a ubiquitous bacteriolytic enzyme synthesized by hepatocytes, neutrophils, and macrophages. Symptomatic liver and gastrointestinal amyloidosis is common, as well as renal involvement. In a small cohort from NAC [101], 4 patients received OLT and 3 received renal transplantation. In all cases, graft function and survival were excellent at the time of censoring, so that LT and renal transplantation appear to be successful for patients with ALys and liver rupture or ESRD.
Fibrinogen amyloidosis (AFib) is a hereditary systemic amyloid disease with visceral, vascular, cardiac, and neurologic involvement, caused by variants of fibrinogen A a-chain. Variant fibrinogen is produced in the liver, and solitary renal allografts fail within 1-7 years due to recurrent amyloidosis [102] with LT combined with renal transplant being the most promising therapies [103-105]. In a report of 22 patients who were evaluated, 9 patients received combined LT and kidney transplantation; most were excluded due to advanced systemic atheromatosis and increased cardiovascular risk associated with AFib. At a median follow-up of 67 months, 6 of 9 patients were alive (67\%), with good allograft function and no amyloidosis; 4 explanted livers were used successfully for domino transplantations. In another report [52], 19 patients with AFib underwent renal transplantation receiving a total of 21 allografts, including 9 patients who received combined LT and kidney transplant. Four of 10 patients with kidney transplant alone died, and among 9 patients who received combined transplants, 3 died in the early postoperative period. Median graft survival in patients who received isolated kidney transplant was 7.3 years and 6.4 years in those who received combined transplants. Five- and 10year graft survival was 85 and $30 \%$, respectively, in patients with an isolated renal transplant, and 63 and $31 \%$ in those with combined LT and renal transplant. Recurrent amyloid was identified in the renal allografts of $7 \mathrm{pa}-$ tients, all of whom had isolated renal transplant, while no patient with combined transplant developed renal allograft amyloid.

Patients with hereditary apolipoprotein AI (apoAI) amyloidosis often develop ESRD, but solid organ transplantation is controversial due to the multisystem and progressive nature of the disease and the risk of recurrence of amyloid in the graft. In a report of 10 patients with apoAI, all of whom received a renal transplant, 2 had both heart and kidney grafts, and 2 received both LT and kidney transplants, followed for 9 years after transplantation, 8 were alive, and 7 had a functioning graft at censoring. The renal transplant of 1 patient failed due to recurrence of amyloid after 25 years. Amyloid disease progression was very slow, and the natural history of the condition was favorably altered in both LT cases.

\section{Conclusions}

Following the introduction of modern highly effective therapies for precursor proteins and advances in solid organ transplantation, with better management of 
complications and improved supportive care, amyloidosis should no longer be considered as a contraindication to solid organ transplantation. The main limitations regarding data robustness are the retrospective nature of the data, the small patient numbers given due to disease rarity, and the presence of selection bias secondary to the absence of clear recommendations for patient selection. Additional data should be collected, preferably in the context of an international collaboration that will help to develop specific and strict selection criteria for each type of amyloidosis and with regard to the primary organ involvement and optimal timing. Key to the success of these procedures is the guidance from highly specialized centers and the involvement of multidisciplinary teams.

\section{Conflict of Interest Statement}

F.T. and D.F. have no disclosures. E.K. has received honoraria/ personal fees from Amgen, Genesis Pharma, Janssen, Takeda, and Prothena, and research grants from Amgen and Janssen. M.A.D. has received honoraria/personal fees from Amgen, BMS, Celgene, GSK, Janssen, and Takeda.

\section{Funding Sources}

No funding was received for this work.

\section{Author Contributions}

F.T., D.F., and E.T. contributed equally to this work.

\section{References}

1 Benson MD, Buxbaum JN, Eisenberg DS, Merlini G, Saraiva MJ, Sekijima Y, et al. Amyloid nomenclature 2018: recommendations by the International Society of Amyloidosis (ISA) nomenclature committee. Amyloid. 2018 Dec;25(4):215-9.

2 Merlini G, Dispenzieri A, Sanchorawala V, Schönland SO, Palladini G, Hawkins PN, et al. Systemic immunoglobulin light chain amyloidosis. Nat Rev Dis Primers. 2018 Oct;4(1): 38.

3 Merlini G, Bellotti V. Molecular mechanisms of amyloidosis. N Engl J Med. 2003 Aug; 349(6):583-96.

4 Kyle RA, Gertz MA. Primary systemic amyloidosis: clinical and laboratory features in 474 cases. Semin Hematol. 1995 Jan;32(1): 45-59.

5 Kastritis E, Dimopoulos MA. Recent advances in the management of AL Amyloidosis. Br J Haematol. 2016 Jan;172(2):170-86.

6 D'Souza A, Dispenzieri A, Wirk B, Zhang MJ, Huang J, Gertz MA, et al. Improved Outcomes After Autologous Hematopoietic Cell Transplantation for Light Chain Amyloidosis: A Center for International Blood and Marrow Transplant Research Study. J Clin Oncol. 2015 Nov;33(32):3741-9.

7 Muchtar E, Gertz MA, Lacy MQ, Go RS, Buadi FK, Dingli D, et al. Ten-year survivors in AL amyloidosis: characteristics and treatment pattern. Br J Haematol. 2019 Dec; 187(5):58894.

8 Hawkins PN, Ando Y, Dispenzeri A, Gonzalez-Duarte A, Adams D, Suhr OB. Evolving landscape in the management of transthyretin amyloidosis. Ann Med. 2015;47(8):625-38.

9 Lachmann HJ, Goodman HJ, Gilbertson JA, Gallimore JR, Sabin CA, Gillmore JD, et al. Natural history and outcome in systemic AA amyloidosis. N Engl J Med. 2007 Jun;356(23): 2361-71.
10 Obici L, Merlini G. AA amyloidosis: basic knowledge, unmet needs and future treatments. Swiss Med Wkly. 2012 May; 142:w13580.

11 Grogan M, Gertz M, McCurdy A, Roeker L, Kyle R, Kushwaha S, et al. Long term outcomes of cardiac transplant for immunoglobulin light chain amyloidosis: The Mayo Clinic experience. World J Transplant. 2016 Jun; 6(2):380-8.

12 Gray Gilstrap L, Niehaus E, Malhotra R, Ton VK, Watts J, Seldin DC, et al. Predictors of survival to orthotopic heart transplant in patients with light chain amyloidosis. J Heart Lung Transplant. 2014 Feb;33(2):149-56.

13 Kristen AV, Kreusser MM, Blum P, Schönland SO, Frankenstein L, Dösch AO, et al. Improved outcomes after heart transplantation for cardiac amyloidosis in the modern era. J Heart Lung Transplant. 2018 May;37(5):6118.

14 Comenzo RL, Zhang Y, Martinez C, Osman $\mathrm{K}$, Herrera GA. The tropism of organ involvement in primary systemic amyloidosis: contributions of Ig V(L) germ line gene use and clonal plasma cell burden. Blood. 2001 Aug; 98(3):714-20.

15 Comenzo RL, Wally J, Kica G, Murray J, Ericsson T, Skinner M, et al. Clonal immunoglobulin light chain variable region germline gene use in AL amyloidosis: association with dominant amyloid-related organ involvement and survival after stem cell transplantation. Br J Haematol. 1999 Sep;106(3):744-51.

16 Kourelis TV, Dasari S, Theis JD, Ramirez-Alvarado M, Kurtin PJ, Gertz MA, et al. Clarifying immunoglobulin gene usage in systemic and localized immunoglobulin light-chain amyloidosis by mass spectrometry. Blood. 2017 Jan;129(3):299-306.

17 Palladini G, Hegenbart U, Milani P, Kimmich C, Foli A, Ho AD, et al. A staging system for renal outcome and early markers of renal response to chemotherapy in AL amyloidosis. Blood. 2014 Oct;124(15):2325-32.

18 Pinney JH, Lachmann HJ, Bansi L, Wechalekar AD, Gilbertson JA, Rowczenio D, et al. Outcome in renal $\mathrm{Al}$ amyloidosis after chemotherapy. J Clin Oncol. 2011 Feb;29(6): 674-81.

19 Kastritis E, Gavriatopoulou M, Roussou M, Migkou M, Fotiou D, Ziogas DC, et al. Renal outcomes in patients with AL amyloidosis: prognostic factors, renal response and the impact of therapy. Am J Hematol. 2017 Jul;92(7): 632-9.

20 Gertz MA, Leung N, Lacy MQ, Dispenzieri A, Zeldenrust SR, Hayman SR, et al. Clinical outcome of immunoglobulin light chain amyloidosis affecting the kidney. Nephrol Dial Transplant. 2009 Oct;24(10):3132-7.

21 Wechalekar AD, Schonland SO, Kastritis E, Gillmore JD, Dimopoulos MA, Lane T, et al. A European collaborative study of treatment outcomes in 346 patients with cardiac stage III AL amyloidosis. Blood. 2013 Apr;121(17):3420-7.

22 Palladini G, Sachchithanantham S, Milani P, Gillmore J, Foli A, Lachmann H, et al. A European collaborative study of cyclophosphamide, bortezomib, and dexamethasone in upfront treatment of systemic AL amyloidosis. Blood. 2015 Jul;126(5):612-5.

23 Dinner S, Witteles W, Afghahi A, Witteles R, Arai S, Lafayette R, et al. Lenalidomide, melphalan and dexamethasone in a population of patients with immunoglobulin light chain amyloidosis with high rates of advanced cardiac involvement. Haematologica. 2013 Oct; 98(10):1593-9.

24 Park MA, Mueller PS, Kyle RA, Larson DR, Plevak MF, Gertz MA. Primary (AL) hepatic amyloidosis: clinical features and natural history in 98 patients. Medicine (Baltimore). 2003 Sep;82(5):291-8. 
25 Gertz MA, Kyle RA. Hepatic amyloidosis (primary $[\mathrm{AL}]$, immunoglobulin light chain): the natural history in 80 patients. Am J Med. 1988 Jul;85(1):73-80.

26 Dispenzieri A, Gertz MA, Kyle RA, Lacy MQ, Burritt MF, Therneau TM, et al. Serum cardiac troponins and $\mathrm{N}$-terminal pro-brain natriuretic peptide: a staging system for primary systemic amyloidosis. J Clin Oncol. 2004 Sep; 22(18):3751-7.

27 Palladini G, Barassi A, Klersy C, Pacciolla R, Milani P, Sarais G, et al. The combination of high-sensitivity cardiac troponin $\mathrm{T}$ (hs-cTnT) at presentation and changes in $\mathrm{N}$-terminal natriuretic peptide type B (NT-proBNP) after chemotherapy best predicts survival in $\mathrm{AL}$ amyloidosis. Blood. 2010 Nov;116(18):342630.

28 Lilleness B, Ruberg FL, Mussinelli R, Doros G, Sanchorawala V. Development and validation of a survival staging system incorporating BNP in patients with light chain amyloidosis. Blood. 2019 Jan;133(3):215-23.

29 Palladini G, Lavatelli F, Russo P, Perlini S, Perfetti V, Bosoni T, et al. Circulating amyloidogenic free light chains and serum $\mathrm{N}$-terminal natriuretic peptide type $\mathrm{B}$ decrease simultaneously in association with improvement of survival in AL. Blood. 2006 May; 107(10):3854-8.

30 Staron A, Burks EJ, Lee JC, Sarosiek S, Sloan JM, Sanchorawala V. Assessment of minimal residual disease using multiparametric flow cytometry in patients with AL amyloidosis. Blood Adv. 2020 Mar;4(5):880-4.

31 Sidana S, Muchtar E, Sidiqi MH, Jevremovic D, Dispenzieri A, Gonsalves W, et al. Impact of minimal residual negativity using next generation flow cytometry on outcomes in light chain amyloidosis. Am J Hematol. 2020 May; 95(5):497-502.

32 Kastritis E, Kostopoulos IV, Terpos E, Paiva B, Fotiou D, Gavriatopoulou M, et al. Evaluation of minimal residual disease using nextgeneration flow cytometry in patients with $\mathrm{AL}$ amyloidosis. Blood Cancer J. 2018 May;8(5): 46.

33 Dispenzieri A, Arendt B, Dasari S, Kohlhagen M, Kourelis T, Kumar SK, et al. Blood mass spectrometry detects residual disease better than standard techniques in light-chain amyloidosis. Blood Cancer J. 2020 Feb;10(2):20.

34 Palladini G, Merlini G. What is new in diagnosis and management of light chain amyloidosis? Blood. 2016 Jul;128(2):159-68.

35 Gertz MA, Lacy MQ, Dispenzieri A, Hayman SR, Kumar S. Transplantation for amyloidosis. Curr Opin Oncol. 2007 Mar;19(2):13641.

36 Gertz MA, Lacy MQ, Dispenzieri A, Kumar SK, Dingli D, Leung N, et al. Refinement in patient selection to reduce treatment-related mortality from autologous stem cell transplantation in amyloidosis. Bone Marrow Transplant. 2013 Apr;48(4):557-61.
37 Kastritis E, Wechalekar AD, Dimopoulos MA, Merlini G, Hawkins PN, Perfetti V, et al. Bortezomib with or without dexamethasone in primary systemic (light chain) amyloidosis. J Clin Oncol. 2010 Feb;28(6):1031-7.

38 Merlini G, Sanchorawala V, Jeffrey Z, Kukreti V, Schoenland S, Jaccard A, et al. LongTerm Outcome of a Phase 1 Study of the Investigational Oral Proteasome Inhibitor (PI) Ixazomib at the Recommended Phase 3 Dose (RP3D) in Patients (Pts) with Relapsed or Refractory Systemic Light-Chain (AL) Amyloidosis (RRAL). Blood. 2014;124(21):3450.

39 Cohen AD, Landau H, Scott EC, Liedtke M, Kaufman JL, Rosenzweig M, et al. Safety and Efficacy of Carfilzomib (CFZ) in PreviouslyTreated Systemic Light-Chain (AL) Amyloidosis. Blood. 2016;128(22):645.

40 Dispenzieri A, Lacy MQ, Zeldenrust SR, Hayman SR, Kumar SK, Geyer SM, et al. The activity of lenalidomide with or without dexamethasone in patients with primary systemic amyloidosis. Blood. 2007 Jan;109(2):465-70.

41 Kastritis E, Terpos E, Roussou M, Gavriatopoulou M, Pamboukas C, Boletis I, et al. A phase $1 / 2$ study of lenalidomide with lowdose oral cyclophosphamide and low-dose dexamethasone (RdC) in $\mathrm{AL}$ amyloidosis. Blood. 2012 Jun;119(23):5384-90.

42 Dispenzieri A, Buadi F, Laumann K, LaPlant B, Hayman SR, Kumar SK, et al. Activity of pomalidomide in patients with immunoglobulin light-chain amyloidosis. Blood. 2012 Jun; 119(23):5397-404.

43 Kaufman GP, Schrier SL, Lafayette RA, Arai S, Witteles RM, Liedtke M. Daratumumab yields rapid and deep hematologic responses in patients with heavily pretreated AL amyloidosis. Blood. 2017 Aug;130(7):900-2.

44 Conner R, Hosenpud JD, Norman DJ, Pantely GA, Cobanoglu A, Starr A. Heart transplantation for cardiac amyloidosis: successful one-year outcome despite recurrence of the disease. J Heart Transplant. 1988 Mar-Apr; $7(2): 165-7$.

45 Dubrey SW, Burke MM, Hawkins PN, Banner NR. Cardiac transplantation for amyloid heart disease: the United Kingdom experience. J Heart Lung Transplant. 2004 Oct; 23(10):1142-53.

46 Davis MK, Kale P, Liedtke M, Schrier S, Arai $\mathrm{S}$, Wheeler M, et al. Outcomes after heart transplantation for amyloid cardiomyopathy in the modern era. Am J Transplant. 2015 Mar;15(3):650-8.

47 Sattianayagam PT, Gibbs SD, Pinney JH, Wechalekar AD, Lachmann HJ, Whelan CJ, et al. Solid organ transplantation in AL amyloidosis. Am J Transplant. 2010 Sep;10(9): 2124-31.

48 Belzer FO, Ashby BS, Gulyassy PF, Powell M. Successful seventeen-hour preservation and transplantation of human-cadaver kidney. $\mathrm{N}$ Engl J Med. 1968 Mar;278(11):608-10.
49 Casserly LF, Fadia A, Sanchorawala V, Seldin DC, Wright DG, Skinner M, et al. High-dose intravenous melphalan with autologous stem cell transplantation in AL amyloidosis-associated end-stage renal disease. Kidney Int. 2003 Mar;63(3):1051-7.

50 Leung N, Griffin MD, Dispenzieri A, Haugen EN, Gloor JM, Schwab TR, et al. Living donor kidney and autologous stem cell transplantation for primary systemic amyloidosis (AL) with predominant renal involvement. Am J Transplant. 2005 Jul;5(7):1660-70.

51 Herrmann SM, Gertz MA, Stegall MD, Dispenzieri A, Cosio FC, Kumar S, et al. Longterm outcomes of patients with light chain amyloidosis (AL) after renal transplantation with or without stem cell transplantation. Nephrol Dial Transplant. 2011 Jun;26(6): 2032-6.

52 Pinney JH, Lachmann HJ, Sattianayagam PT, Gibbs SD, Wechalekar AD, Venner CP, et al. Renal transplantation in systemic amyloidosis-importance of amyloid fibril type and precursor protein abundance. Am J Transplant. $2013 \mathrm{Feb}$;13(2):433-41.

53 Angel-Korman A, Stern L, Sarosiek S, Sloan JM, Doros G, Sanchorawala V, et al. Longterm outcome of kidney transplantation in AL amyloidosis. Kidney Int. 2019 Feb;95(2): 405-11.

54 Merlini G, Remuzzi G. Autologous stem cell and kidney transplantation for primary amyloidosis associated with ESRD: which should come first? Am J Transplant. 2005 Jul;5(7): 1585-6.

55 Sathick IJ, Rosenbaum CA, Gutgarts V, Landau H. Kidney transplantation in AL Amyloidosis: is it time to maximize access? $\mathrm{Br} \mathrm{J}$ Haematol. 2020 Feb;188(3):e1-4.

56 Nuvolone M, Merlini G. Improved outcomes for kidney transplantation in AL amyloidosis: impact on practice. Kidney Int. 2019 Feb; 95(2):258-60.

57 Dubrey SW, Cha K, Anderson J, Chamarthi B, Reisinger J, Skinner M, et al. The clinical features of immunoglobulin light-chain (AL) amyloidosis with heart involvement. QJM. 1998 Feb;91(2):141-57.

58 Merlini G, Palladini G. Treating advanced cardiac damage in light chain amyloidosis: still an unmet need. Haematologica. 2014 Sep; 99(9):1407-9.

59 Hall R, Hawkins PN. Cardiac transplantation for AL amyloidosis. BMJ. 1994 Oct;309(6962): $1135-7$.

60 Dubrey SW, Burke MM, Khaghani A, Hawkins PN, Yacoub MH, Banner NR. Long term results of heart transplantation in patients with amyloid heart disease. Heart. 2001 Feb;85(2):202-7.

61 Lacy MQ, Dispenzieri A, Hayman SR, Kumar S, Kyle RA, Rajkumar SV, et al. Autologous stem cell transplant after heart transplant for light chain (Al) amyloid cardiomyopathy. J Heart Lung Transplant. 2008 Aug;27(8):823-

Theodorakakou/Fotiou/Dimopoulos/ Kastritis 
62 Gillmore JD, Goodman HJ, Lachmann HJ, Offer M, Wechalekar AD, Joshi J, et al. Sequential heart and autologous stem cell transplantation for systemic AL amyloidosis. Blood. 2006 Feb;107(3):1227-9.

63 Mehra MR, Canter CE, Hannan MM, Semigran MJ, Uber PA, Baran DA, et al.; International Society for Heart Lung Transplantation (ISHLT) Infectious Diseases, Pediatric and Heart Failure and Transplantation Councils. The 2016 International Society for Heart Lung Transplantation listing criteria for heart transplantation: A 10-year update. J Heart Lung Transplant. 2016 Jan;35(1):1-23.

64 Dey BR, Chung SS, Spitzer TR, Zheng H, Macgillivray TE, Seldin DC, et al. Cardiac transplantation followed by dose-intensive melphalan and autologous stem-cell transplantation for light chain amyloidosis and heart failure. Transplantation. 2010 Oct; 90 (8): 905-11.

65 Gertz MA, Lacy MQ, Dispenzieri A, Buadi FK, Dingli D, Hayman SR, et al. Stem cell transplantation compared with melphalan plus dexamethasone in the treatment of immunoglobulin light-chain amyloidosis. Cancer. 2016 Jul;122(14):2197-205.

66 Kastritis E, Leleu X, Arnulf B, Zamagni E, Cibeira MT, Kwok F, et al. A Randomized Phase III Trial of Melphalan and Dexamethasone (MDex) Versus Bortezomib, Melphalan and Dexamethasone (BMDex) for Untreated Patients with AL Amyloidosis. Blood. 2016; 128(22):646.

67 Gran C, Borg Bruchfeld J, Ellin F, Nahi H. Rapid Complete Response to Single-Agent Bcl-2 Inhibitor Venetoclax in a Heart-Transplanted Patient with Triple Refractory Immunoglobulin Light-Chain Amyloidosis. Acta Haematol. 2020, Epub ahead of print.

68 Swiecicki PL, Edwards BS, Kushwaha SS, Dispenzieri A, Park SJ, Gertz MA. Left ventricular device implantation for advanced cardiac amyloidosis. J Heart Lung Transplant. 2013 May;32(5):563-8.

69 Kittleson MM, Cole RM, Patel J, Ramzy D, Passano E, Chang DH, et al. Mechanical circulatory support for cardiac amyloidosis. Clin Transplant. 2019 Oct;33(10):e13663.

70 Al-Lawati K, Lim HS. Temporary Biventricular Assist Device to Bridge a Patient With Cardiogenic Shock Due to AL Amyloidosis to Heart Transplantation. Artif Organs. 2017 Dec;41(12):1183-4.

71 Gkouziouta A, Farmakis D, Manginas A, Sfyrakis P, Saroglou G, Adamopoulos S, et al. Double organ transplantation in cardiac amyloidosis. J Cardiovasc Med (Hagerstown). 2016 Feb;17(2):126-9.

72 Russo P, Palladini G, Foli A, Zenone Bragotti L, Milani P, Nuvolone M, et al. Liver involvement as the hallmark of aggressive disease in light chain amyloidosis: distinctive clinical features and role of light chain type in $225 \mathrm{pa}$ tients. Amyloid. 2011 Jun;18(Suppl 1):92-3.
73 Maurer MS, Elliott P, Comenzo R, Semigran M, Rapezzi C. Addressing Common Questions Encountered in the Diagnosis and Management of Cardiac Amyloidosis. Circulation. 2017 Apr;135(14):1357-77.

74 Suhr OB, Larsson M, Ericzon BG, Wilczek HE; FAPWTR's investigators. Survival After Transplantation in Patients With Mutations Other Than Val30Met: Extracts From the FAP World Transplant Registry. Transplantation. 2016 Feb;100(2):373-81

75 Holmgren G, Steen L, Ekstedt J, Groth CG, Ericzon BG, Eriksson S, et al. Biochemical effect of liver transplantation in two Swedish patients with familial amyloidotic polyneuropathy (FAP-met30). Clin Genet. 1991 Sep; $40(3): 242-6$.

76 Yamashita T, Ando Y, Okamoto S, Misumi Y, Hirahara T, Ueda M, et al. Long-term survival after liver transplantation in patients with familial amyloid polyneuropathy. Neurology. 2012 Feb;78(9):637-43.

77 Carvalho A, Rocha A, Lobato L. Liver transplantation in transthyretin amyloidosis: issues and challenges. Liver Transpl. 2015 Mar; 21(3):282-92.

78 Wilczek HE, Larsson M, Ericzon BG; FAPWTR. Long-term data from the Familial Amyloidotic Polyneuropathy World Transplant Registry (FAPWTR). Amyloid. 2011 Jun;18(Suppl 1):193-5.

79 Santopaolo F, Lenci I, Bosa A, Angelico M, Milana M, Baiocchi L. Domino Liver Transplantation: where are we Now? Rev Recent Clin Trials. 2019;14(3):183-8.

80 Stangou AJ, Heaton ND, Hawkins PN. Transmission of systemic transthyretin amyloidosis by means of domino liver transplantation. $\mathrm{N}$ Engl J Med. 2005 Jun;352(22):2356.

81 Lladó L, Baliellas C, Casasnovas C, Ferrer I, Fabregat J, Ramos E, et al. Risk of transmission of systemic transthyretin amyloidosis after domino liver transplantation. Liver Transpl. 2010 Dec;16(12):1386-92.

82 Vollmar J, Schmid JC, Hoppe-Lotichius M, Barreiros AP, Azizi M, Emrich T, et al. Progression of transthyretin (TTR) amyloidosis in donors and recipients after domino liver transplantation-a prospective single-center cohort study. Transpl Int. 2018 Nov;31(11):1207-15.

83 Okamoto S, Zhao Y, Lindqvist P, Backman C, Ericzon BG, Wijayatunga $\mathrm{P}$, et al. Development of cardiomyopathy after liver transplantation in Swedish hereditary transthyretin amyloidosis (ATTR) patients. Amyloid. 2011 Dec;18(4):200-5.

84 Ammirati E, Marziliano N, Vittori C, Pedrotti P, Bramerio MA, Motta V, et al. The first Caucasian patient with p.Val122Ile mutatedtransthyretin cardiac amyloidosis treated with isolated heart transplantation. Amyloid. 2012 Jun;19(2):113-7.

85 Thenappan T, Fedson S, Rich J, Murks C, Husain A, Pogoriler J, et al. Isolated heart transplantation for familial transthyretin (TTR) V122I cardiac amyloidosis. Amyloid. 2014 Jun;21(2):120-3.
86 Nelson LM, Penninga L, Sander K, Hansen $\mathrm{PB}$, Villadsen GE, Rasmussen A, et al. Longterm outcome in patients treated with combined heart and liver transplantation for familial amyloidotic cardiomyopathy. Clin Transplant. 2013 Mar-Apr;27(2):203-9.

87 Nardo B, Beltempo P, Bertelli R, Montalti R, Vivarelli M, Cescon M, et al. Combined heart and liver transplantation in four adults with familial amyloidosis: experience of a single center. Transplant Proc. 2004 Apr;36(3): 645-7.

88 Rosenbaum AN, AbouEzzeddine OF, Grogan M, Dispenzieri A, Kushwaha S, Clavell A, et al. Outcomes After Cardiac Transplant for Wild Type Transthyretin Amyloidosis. Transplantation. 2018 Nov;102(11):1909-13.

89 Coelho T, Merlini G, Bulawa CE, Fleming JA, Judge DP, Kelly JW, et al. Mechanism of Action and Clinical Application of Tafamidis in Hereditary Transthyretin Amyloidosis. Neurol Ther. 2016 Jun;5(1):1-25.

90 Castaño A, Drachman BM, Judge D, Maurer MS. Natural history and therapy of TTR-cardiac amyloidosis: emerging disease-modifying therapies from organ transplantation to stabilizer and silencer drugs. Heart Fail Rev. 2015 Mar;20(2):163-78.

91 Maurer MS, Schwartz JH, Gundapaneni B, Elliott PM, Merlini G, Waddington-Cruz M, et al.; ATTR-ACT Study Investigators. Tafamidis Treatment for Patients with Transthyretin Amyloid Cardiomyopathy. N Engl J Med. 2018 Sep;379(11):1007-16.

92 Benson MD, Waddington-Cruz M, Berk JL, Polydefkis M, Dyck PJ, Wang AK, et al. Inotersen Treatment for Patients with Hereditary Transthyretin Amyloidosis. N Engl J Med. 2018 Jul;379(1):22-31.

93 Adams D, Gonzalez-Duarte A, O'Riordan WD, Yang CC, Ueda M, Kristen AV, et al. Patisiran, an RNAi Therapeutic, for Hereditary Transthyretin Amyloidosis. N Engl J Med. 2018 Jul;379(1):11-21.

94 Solomon SD, Adams D, Kristen A, Grogan M, González-Duarte A, Maurer MS, et al. Effects of Patisiran, an RNA Interference Therapeutic, on Cardiac Parameters in Patients With Hereditary Transthyretin-Mediated Amyloidosis. Circulation. 2019 Jan;139(4):431-43.

95 Dasgupta NR, Rissing SM, Smith J, Jung J, Benson MD. Inotersen therapy of transthyretin amyloid cardiomyopathy. Amyloid. 2020 Mar;27(1):52-8.

96 Dember LM, Hawkins PN, Hazenberg BP, Gorevic PD, Merlini G, Butrimiene I, et al.; Eprodisate for AA Amyloidosis Trial Group. Eprodisate for the treatment of renal disease in AA amyloidosis. N Engl J Med. 2007 Jun; 356(23):2349-60.

97 Kofman T, Grimbert P, Canouï-Poitrine F, Zuber J, Garrigue V, Mousson C, et al. Renal transplantation in patients with AA amyloidosis nephropathy: results from a French multicenter study. Am J Transplant. 2011 Nov;11(11):2423-31. 
98 Trabulus S, Korkmaz M, Kaya E, Seyahi N. Canakinumab treatment in kidney transplant recipients with AA amyloidosis due to familial Mediterranean fever. Clin Transplant. 2018 Aug;32(8):e13345.

99 Abedi AS, Nakhjavani JM, Etemadi J. Longterm outcome of renal transplantation in patients with familial Mediterranean fever amyloidosis: a single-center experience. Transplant Proc. 2013;45(10):3502-4.

100 Moser C, Pohl G, Haslinger I, Knapp S, Rowczenio D, Russel T, et al. Successful treatment of familial Mediterranean fever with Anakinra and outcome after renal transplantation. Nephrol Dial Transplant. 2009 Feb;24(2):676-8.
101 Sattianayagam PT, Gibbs SD, Rowczenio D, Pinney JH, Wechalekar AD, Gilbertson JA, et al. Hereditary lysozyme amyloidosisphenotypic heterogeneity and the role of solid organ transplantation. J Intern Med. 2012 Jul;272(1):36-44.

102 Hamidi Asl L, Liepnieks JJ, Uemichi T, Rebibou JM, Justrabo E, Droz D, et al. Renal amyloidosis with a frame shift mutation in fibrinogen aalpha-chain gene producing a novel amyloid protein. Blood. 1997 Dec; 90(12):4799-805.
103 Mousson C, Heyd B, Justrabo E, Rebibou JM, Tanter Y, Miguet JP, et al. Successful hepatorenal transplantation in hereditary amyloidosis caused by a frame-shift mutation in fibrinogen Aalpha-chain gene. Am J Transplant. 2006 Mar;6(3):632-5.

104 Zeldenrust S, Gertz M, Uemichi T, Björnsson J, Wiesner R, Schwab T, et al. Orthotopic liver transplantation for hereditary fibrinogen amyloidosis. Transplantation. 2003 Feb;75(4):560-1.

105 Gillmore JD, Booth DR, Rela M, Heaton ND, Rahman V, Stangou AJ, et al. Curative hepatorenal transplantation in systemic amyloidosis caused by the Glu526Val fibrinogen alpha-chain variant in an English family. QJM. 2000 May;93(5):269-75. 